\title{
A Systematic Controller Design for a Photovoltaic Generator with Boost Converter Using Integral State Feedback Control
}

\author{
Zeineb Rania Labidi \\ Laboratory of Application of Energy, \\ Efficiency and Renewable Energies, \\ Faculty of Sciences of Tunis, Tunis El \\ Manar University, Tunis, Tunisia \\ zeinebrania.labidi@fst.utm.tn
}

\author{
Horst Schulte \\ Department of Engineering, \\ University of Applied Sciences for \\ Engineering and Economics, \\ Berlin, Germany \\ horst.schulte@htw-berlin.de
}

\author{
Abdelkader Mami \\ Laboratory of Application of Energy, \\ Efficiency and Renewable Energies, \\ Faculty of Sciences of Tunis, Tunis El \\ Manar University, Tunis, Tunisia \\ abdelkader.mami@fst.utm.tn
}

\begin{abstract}
In this paper, a systematic controller design for a photovoltaic generator with boost converter using integral state feedback control is proposed. It is demonstrated that the statespace feedback enables the extraction of maximum available power under variable loads. For this purpose, a control-oriented state-space model of a photovoltaic array connected to a DC load by a boost converter is derived. This model is then linearized by one working point, but no further simplifications are made. The design-oriented model contains the dynamics of PV generator, boost converter, and the load. The controller design is based on the augmented model with an integral component. The controller is validated by a detailed plant model implemented in Simscape. The robustness of the controller with variable solar irradiation and DC load changes is demonstrated.
\end{abstract}

Keywords-feedback control; boost converter; maximum power point tracking (MPPT); state-space modeling; photovoltaic generator

\section{INTRODUCTION}

The increasing need for energy, the high cost of generating electricity, and the sunlight availability made necessary the exploitation of the advantages of power electronics and control techniques which improve the efficiency of solar systems [1]. The evolution and development of the solar generator is a challenge for researchers as an optimal solution to the production of low-cost power [2]. Studying photovoltaic generators using state-space systems for mathematical modeling allows not only better understanding but also a modern, straightforward approach that will be based on a state feedback controller or an observer-based feedback controller. Authors in [3-6] did not consider the dynamic behavior and the non-linearity of the photovoltaic system, especially the interaction with the converters, which transmit power to the load, nor did they deal with the reliability and stability of the closed-loop control system. Hence, the impact of PV generators on power devices has been neglected [7]. In our case, we considered this effect because the non-linearity of the PV cell can affect the stability and robustness of the system. Authors in [8-10] used classic maximum power point tracking (MPPT) algorithms, such as perturb and observe (P\&O) and incremental conductance (IC), as a way to control the converter [11]. Instead of P\&O MPPT heuristics, a state feedback controller approach to achieve optimal operation was proposed, where the reference voltage of the PV systems is calculated by the $\mathrm{P} / \mathrm{U}$ curve of the PV cells. In this approach, the maximum power point tracking is a set point controlled by regulating the output voltage of the PV array. Furthermore, the dynamics of the system could be better tuned by pole-placement based on the knowledge of the system matrix, the input matrix of the plant, and the desired poles in the closed-loop system. Authors in [12] adapted a state-space feedback approach to a DC-DC converter in PV systems. They used a linear model to represent the PV generator in the system matrix. In the model, the single diode equivalent circuit of the PV array was limited to the distribution level of the voltage source and equivalent resistance, so the behavior of the diode was neglected. Authors in [13] also dealt with the PV array block using an equivalent linearized model of a voltage source, so the non-linearity of the generator was neglected, and the influence of the sun was not included in the control strategy. Furthermore, the study did not consider load change scenarios and the influence of fluctuating sun irradiation on the closed-loop dynamics.

The main contribution of the current work is a systematic state feedback controller design based on a proposed holistic state space model of the PV system that contains the model of the PV array as the current source, the averaging model of the boost converter, and the DC load. The state-space model has three state variables: the output voltage of the PV array, the current through the induction of the booster, and the voltage at the capacitor. The input variables are the controllable duty cycle and the incontrollable input of the sun irradiation. The controller validation is carried out using a detailed Simscape model of the plant. The results are discussed and compared with well-established methods, such as power optimization by the MPPT algorithm.

\section{PV PANEL MODELING}

In this section we will describe two modeling topologies for the single diode equivalent circuit of the PV array: one includes

Corresponding author: Zeineb Rania Labidi 
the devices presented in Simscape (Block set/Tool box in Simulink/Matlab) and the other includes the mathematical equations describing the component of the PV array using the state-space model approach. The state-space model is validated by comparing it with the Simscape model.

\section{A. Simscape Model}

The PV array block presented in Matlab/Simulink is modeled according to System Advisor Model (SAM) from the National Renewable Energy Laboratory (NREL) to perform depending on the type and module defined [14-16]. The panel model defined in this work is Kaneka GSA 060, the PV array contains 5 parallel strings, each string containing 5 modules connected in series to produce maximum power of $1.5 \mathrm{~kW}$ at $1000 \mathrm{~W} / \mathrm{m}^{2}$. The characterizing $\mathrm{I} / \mathrm{U}$ and $\mathrm{P} / \mathrm{U}$ curves of the $\mathrm{PV}$ array are shown in Figure 1.
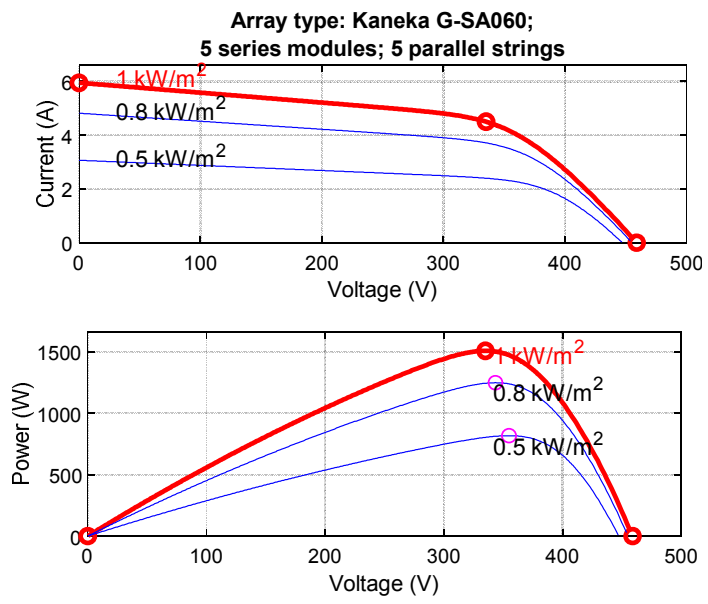

Fig. 1. Parameter curves of the PV Generator

\section{B. State-Space Model}

The state-space model is illustrated by the state equations that contain the derivatives of the state variable that stores the energy as inductors and capacitances [17]. Thus, by adopting Kirchoff's laws on the electrical circuit (Figure 2) that represents the system, the state space equations are:

$$
\begin{aligned}
& \frac{d V_{p v}}{d t}=\frac{R_{s h}}{C_{e}\left(R_{s h}+R_{s}\right)} i_{L d}-\frac{R+R_{s h}+R_{s}}{R C_{e}\left(R_{s h}+R_{s}\right)} V_{p v} \\
& \mathrm{I}_{\mathrm{Ld}}=\mathrm{I}_{\mathrm{L}}-\mathrm{I}_{\mathrm{d}} \\
& \mathrm{I}_{\mathrm{d}}=\mathrm{I}_{0}\left[\exp \left(\frac{\mathrm{V}_{\mathrm{d}}}{\mathrm{V}_{\mathrm{T}}}\right)-1\right]+\frac{\mathrm{V}_{\mathrm{d}}}{\mathrm{R}_{\mathrm{sh}}}+\frac{\mathrm{V}_{\mathrm{d}}}{\mathrm{R}_{\mathrm{sh}}} \mathrm{S}_{\text {ref }} \\
& \mathrm{I}_{\mathrm{L}}=\frac{\mathrm{s}}{\mathrm{S}_{\text {ref }}}\left[\mathrm{I}_{\text {Lref }}+\alpha_{\mathrm{isc}}\left(\mathrm{T}_{\text {cell, } \mathrm{k}}-\mathrm{T}_{\text {ref }, \mathrm{k}}\right)\right] \\
& \mathrm{V}_{\mathrm{T}}=\frac{\mathrm{KT}}{\mathrm{q}} \mathrm{n}_{\mathrm{I}} \mathrm{N}_{\text {cell }} \mathrm{N}_{\text {ser }} \\
& \mathrm{V}_{\mathrm{d}}=\mathrm{V}_{\mathrm{pv}}+\mathrm{R}_{\mathrm{s}} \mathrm{I}_{\mathrm{pv}}
\end{aligned}
$$

\section{Validation of the State-Space Model of the PV Generator}

Authors in $[8,12,13,17]$ did not take into account the PV panel as a non-linear independent system that could negatively influence the results of the approach used to control the boost converter for maximum power, especially in state-space modeling. Hence, a separate modeling and study of the PV system is very important. Shunt resistance and diode compensation elements must not be neglected when building the state space model because they strongly influence the dynamics of the system, and without them the results are not accurate and do not reflect the real behavior of the system (i.e. the PV cells). As shown in Figure 3, we validated the state space model because PV voltage and current are identical to those extracted by the Simscape model.

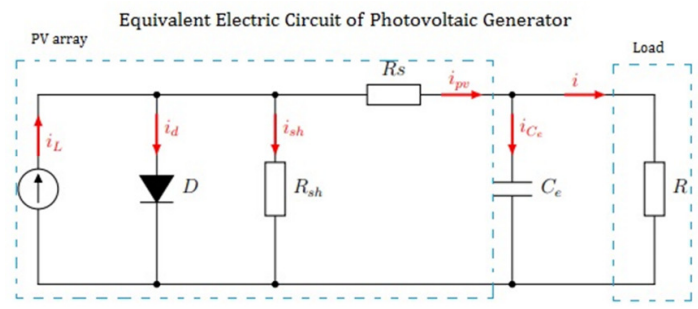

Fig. 2. Singe diode equivalent electric circuit of the PV Generator

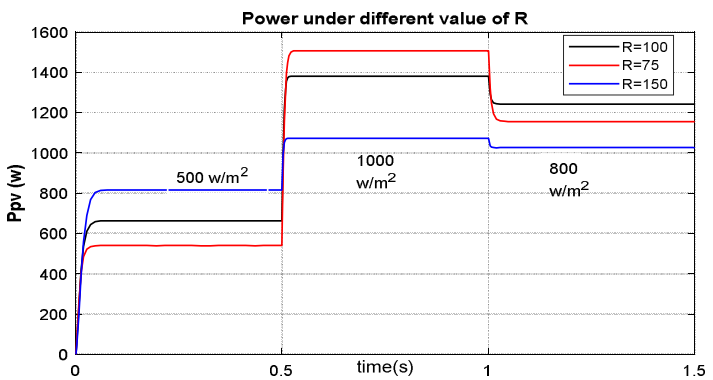

Fig. 3. Power under different values of irradiation and load

Power under different values of irradiation and load is power for the same values of irradiation (i.e. it never reaches maximum power). The direct connection between the PV array and the load does not give maximum power independently from sunlight or load. The direct installation is useful only if we have constant light irradiation and constant load [18]. Then we need to choose the appropriate load for the available light, which is not practical, especially in an irregular system.

\section{BOOST CONVERTER MODELING}

In this section we will present the characteristics of the boost converter and the state-space model using averaging technique to extract the system and its input matrix.

\section{A. Boost Converter}

The boost converter shown in Figure 4 is a switched-mode supply which can increase the input voltage to the desired output voltage [19]. Its fundamental function is to cut the input voltage by switching it on and off very quickly, in which the transistor serves as the switch. The cutting consists of accumulating energy and transferring it to the load through interrupting the current cyclically. When the transistor is closed, the inductance $\mathrm{L}$ stores the energy in a magnetic form, so when the IGBT is opened, the energy goes to the capacitor $\mathrm{C}$ to aliment the load while the inductance receives more energy from the source. The timing in switching on and off the 
transistor is very important because it allows a stable voltage for the load, which is called duty cycle. As described in [20], some design rules must be followed and verified for the boost converter to operate well: The load $(\mathrm{R}>\mathrm{R}$ PV) must always be superior to the resistance of the PV defined in (9) because the duty cycle must be between 0 and 1 . Equations (7) and (8) describe two other important properties of the boost converter: the input voltage must be less or equal (i.e. the case when the duty cycle is equal to 0 ) to the voltage output and the input current must be greater or equal to the current output.

$$
\begin{aligned}
& \alpha=1-\frac{V_{p v}}{V_{D C}} \\
& \alpha=1-\frac{I_{D C}}{I_{p v}} \\
& R_{p v}=\frac{V_{p v}}{I_{p v}}
\end{aligned}
$$

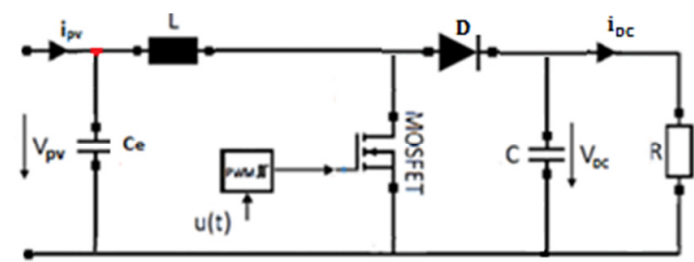

Fig. 4. Circuit of the boost converter

\section{B. State Space Modeling of the Boost Converter}

In the first step, we validated the state-space model of the PV array connected to a simple load, as previously mentioned. This step is very important for the dynamic interactions between the PV block, the boost converter, and the load. The irradiation input strongly influences the system response, which is precisely the function of the controller. The next step is to add the boost converter, but without the feedback controller. We need to validate and compare this model with the Simscape model so that we can work on the controller. In this stage, the control input of the boost is a PWM Simscape device provided by Simulink/Matlab, in which the duty cycle is equal to 0.5 .

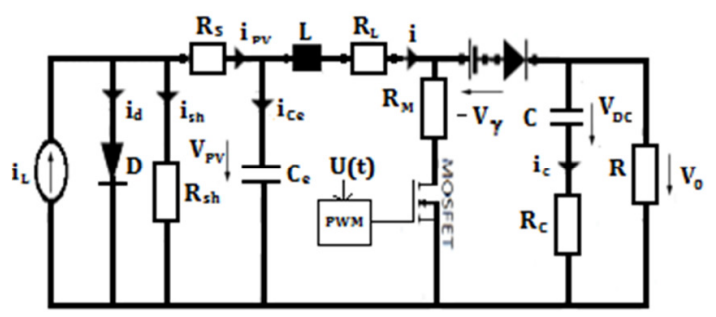

Fig. 5. Equivalent electrical circuit of the system

The state equations of the system in on and off modes will be extracted according to the equivalent electrical circuit of the PV generator (Figure 2) connected to the load through the boost converter presented in Figure 4. Using the averaging technique, a generalized model for both modes with three states is derived. The on mode of the system is illustrated in Figure 6, where input is controllable. According to (2), the input $i_{L}$, which represents the photogenerated current proportional to the sun light, is uncontrollable and can be considered a disturbance. Equations (10)-(12) describe the state-space mathematic modeling of the on mode.

$$
\begin{aligned}
& \frac{d V_{P V}}{d t}=\frac{1}{C_{e}\left(R_{S h}+R_{S}\right)} V_{P V}-\frac{1}{C_{e}} i+\frac{R_{S h}}{C_{e}\left(R_{s h}+R_{s}\right)} i_{L d} \\
& \frac{d i}{d t}=\frac{1}{L} V_{P V}-\frac{\left(R_{L}+R_{M}\right)}{L} i \\
& \frac{d V_{D C}}{d t}=-\frac{1}{C\left(R+R_{C}\right)} V_{D C}
\end{aligned}
$$

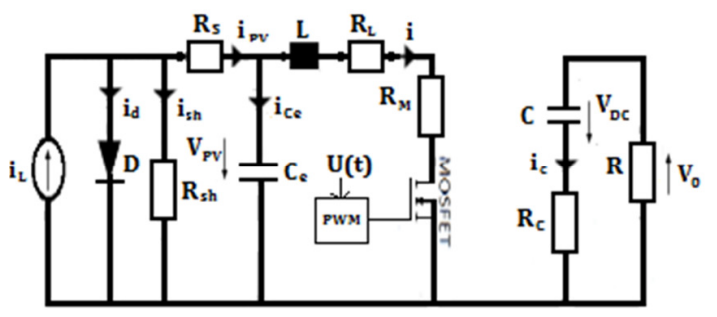

Fig. 6. On mode of the system

Equations (13)-(15) represent the dynamic state-space modeling of the off stage illustrated in Figure 7 . We note that (10) and (13) are equal, which is obvious because the dynamics of the system on the photovoltaic generator side do not change in the on and off modes.

$$
\begin{aligned}
& \frac{d V_{P V}}{d t}=-\frac{1}{C_{e}\left(R_{S h}+R_{S}\right)} V_{P V}-\frac{1}{C_{e}} i+\frac{R_{S h}}{C_{e}\left(R_{S h}+R_{S}\right)} i_{L d} \\
& \frac{d i}{d t}=\frac{1}{L} V_{P V}-\left(\frac{R R_{C}+R_{L} R_{c}+R R_{L}}{L\left(R_{C}+R\right)}\right) i-\frac{R}{L\left(R_{C}+R\right)} V_{D C}-\frac{1}{L} V_{V} \\
& \frac{d V_{D C}}{d t}=\frac{R}{C\left(R+R_{C}\right)} i-\frac{1}{C\left(R+R_{C}\right)} V_{D C}
\end{aligned}
$$

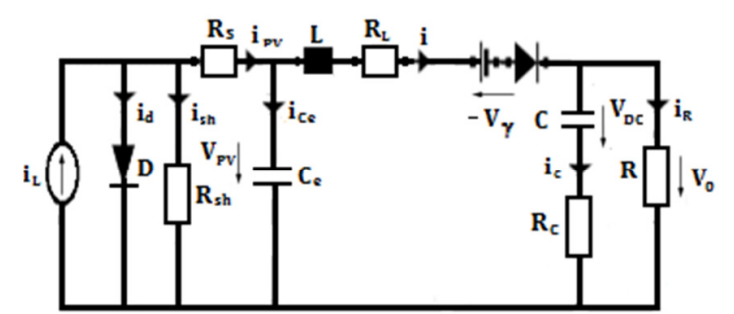

Fig. 7. Off mode of the system

The differential equations of on and off modes can be summarized according to (16). The state space averaging system [21], which combines both time switches, is presented in (20) by using (17):

$$
\begin{aligned}
& \dot{x}(t)=A x(t)+B(x) u(t)+D \\
& \dot{x}(t)=\dot{x}_{\text {on }} u+\dot{x}_{\text {off }}(1-u)
\end{aligned}
$$

where the input $u$ is related to the switch mode:

$\mathrm{S}=\left\{\begin{array}{cl}\text { ON } ; & \text { MOSFET ON } \\ \text { OFF; } & \text { MOSFET OFF }\end{array}\right.$

with $S_{O N}(u)=u, \quad S_{O F F}(u)=1-u, \quad \mathrm{u} \in[0,1]$. 


$$
\begin{aligned}
& \underline{x}=\left(\begin{array}{c}
V_{P V} \\
i \\
V_{D C}
\end{array}\right)=\left(\begin{array}{l}
x_{1} \\
x_{2} \\
x_{3}
\end{array}\right) \\
& \underline{u}=\left(\begin{array}{c}
u_{d} \\
i_{L d}
\end{array}\right)=\left(\begin{array}{l}
u_{1} \\
u_{2}
\end{array}\right)
\end{aligned}
$$

\section{Validation of the State-Space Model}

The state-space model is implemented in Simulink/Matlab and compared to the Simscape model. Figure 8 shows the simulation results under variable irradiation and load. The results demonstrate that the dynamic behavior of the statespace model is equivalent to the Simscape model, which confirms the validation of the modeling. In addition, the design rules of the boost introduced above are verified. Therefore, $V_{p v}<V_{D C}$ and $i_{p v}>i_{D C}$ is fulfilled according to (9), and $R>R_{P V}$.

(a)

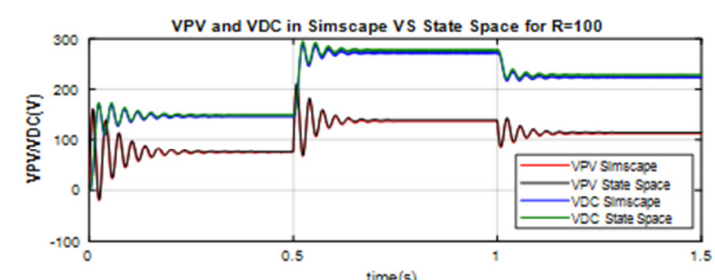

iPV and iDC in Simscape VS State Space for $R=100$

(b)

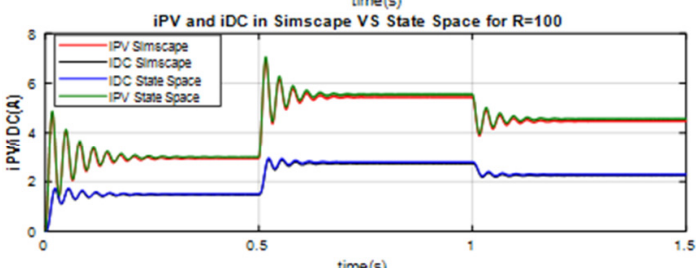

VPV and VDC in Simscape VS State Space for $R=150$

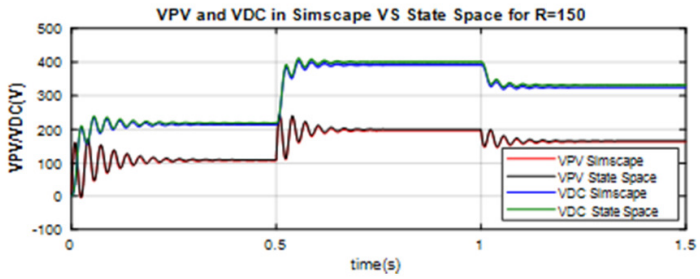

iPV and IDC in Simscape VS State Space for $R=150$

(d)

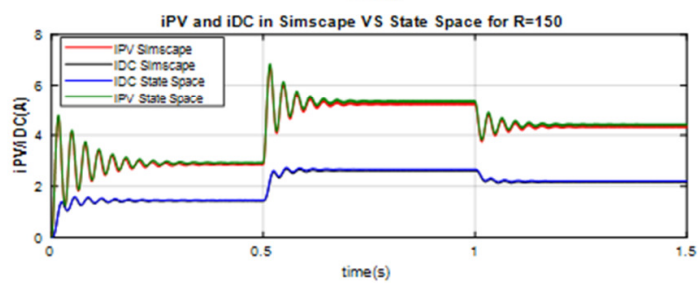

Fig. 8. Comparison between simscape and state space (a), (b) for $\mathrm{R}=100$ and (c), (d) for $\mathrm{R}=150$

\section{STATE SPACE FEEDBACK ONTROLLER}

In this section, we will describe the steps used to build the integral state feedback controller. First, the system (20) around an operating point using the Taylor series is linearized without neglecting the parts of the system. This step is important in dealing with the dynamic matching between the PV panel and the load impedance in the control design.

$$
\begin{aligned}
& \dot{x}=\left[\begin{array}{ccc}
-\frac{1}{C_{e}\left(R_{s h}+R_{s}\right)} & -\frac{1}{C_{e}} & 0 \\
\frac{1}{L} & -\left(\frac{R R_{C}+R_{L} R_{C}+R R_{L}}{L\left(R_{c}+R\right)}\right) & -\frac{R}{L\left(R_{c}+R\right)} \\
0 & \frac{R}{C\left(R+R_{c}\right)} & -\frac{1}{C\left(R+R_{c}\right)}
\end{array}\right]\left[\begin{array}{l}
x_{1} \\
x_{2} \\
x_{3}
\end{array}\right] \\
& +\left[\begin{array}{c}
\frac{R_{S h}}{C_{e}\left(R_{S h}+R_{S}\right)} \\
0 \\
0
\end{array}\right] u_{2}+\left[\begin{array}{c}
\frac{R_{c} R-R_{M} R_{c}-R_{M} R}{L\left(R_{c}+R\right)} X_{2}+\frac{R}{L\left(R_{c}+R\right)} X_{3}+\frac{1}{L} V_{\gamma} \\
-\frac{R}{C\left(R+R_{c}\right)} X_{2}
\end{array}\right] u_{1} \\
& +\left[\begin{array}{c}
0 \\
-\frac{1}{L} \\
0
\end{array}\right] V_{\gamma}
\end{aligned}
$$

\section{A. Linearization of the State Space Equations}

The first step in building the controller is to linearize the state equation (20) around a stationary operating point $\left(x_{c}, u_{c}\right)$, which is characterized as $\dot{x}=f\left(x_{c}, u_{c}\right)=0$, where $u_{c}=\left(\begin{array}{l}u_{1} \\ u_{2}\end{array}\right)$ and $x_{c}=\left(\begin{array}{l}x_{1 c} \\ x_{2 c} \\ x_{3 c}\end{array}\right)$, see (18) and (19).

Then:

$$
\begin{aligned}
& \mathrm{A} x_{c}+\mathrm{B}\left(x_{c}\right) 0.5=0 \rightarrow \\
& A 1 x_{c}+B 1=0
\end{aligned}
$$

By setting $u_{1}=0.5$ and $u_{2}=1$ (19) the matrices (20) in consideration of (21) are given as follows:

$$
\begin{aligned}
& A 1=\left[\begin{array}{ccc}
-\frac{1}{C_{e}\left(R_{S h}+R_{S}\right)} & -\frac{1}{C_{e}} & 0 \\
\frac{1}{L} & -\left(\frac{R R_{C}+R_{L} R_{c}+R R_{L}+\left(0.5 \cdot\left(R_{C} R-R_{M} R_{c}-R_{M} R\right)\right)}{L\left(R_{c}+R\right)}\right) & -\frac{0.5 R}{L\left(R_{c}+R\right)} \\
0 & \frac{0.5 R}{C\left(R+R_{C}\right)} & -\frac{1}{C\left(R+R_{c}\right)}
\end{array}\right] \\
& B 1=\left[\begin{array}{c}
\frac{R_{S h}}{C_{e}\left(R_{S h}+R_{S}\right)} \\
\frac{0.5}{L} V_{\gamma} \\
0
\end{array}\right]
\end{aligned}
$$

Then according to (21) the equilibrium value of $x_{c}$ is:

$$
x c=-i n v(A 1) B 1=\left[\begin{array}{c}
21.1584 \\
0.8624 \\
43.1183
\end{array}\right]
$$

After calculating the equilibrium point by imposing $\dot{x}=0$, we linearize the system around that operating point by using Taylor series.

$$
\begin{aligned}
& \dot{x}=f\left(x_{c}, u_{c}\right)=0 \rightarrow \\
& \Delta \dot{x}=\tilde{A} \underline{\Delta x}+\tilde{B} \underline{\Delta u}
\end{aligned}
$$

where $\tilde{A}=\frac{\partial\left(A x+B(x) u_{1}\right)}{\partial x}=\left(A+\frac{\partial B(x)}{\partial x} u_{1}\right)$

and $\left.\quad \tilde{B}=\frac{\partial\left(A x+B(x) u_{1}\right)}{\partial u_{1}}=B\left(x_{c}\right)\right)$

$\underline{\Delta x}=x-x_{c} ; \underline{\Delta u}=u-u_{c}$ (30):

From the state matrix of the system (20) we extract (29) and 


$$
\begin{aligned}
& A=\left[\begin{array}{ccc}
-\frac{1}{C_{e}\left(R_{S h}+R_{S}\right)} & -\frac{1}{C_{e}} & 0 \\
\frac{1}{L} & -\left(\frac{R R_{C}+R_{L} R_{C}+R R_{L}}{L\left(R_{C}+R\right)}\right) & -\frac{R}{L\left(R_{C}+R\right)} \\
0 & \frac{R}{C\left(R+R_{C}\right)} & -\frac{1}{C\left(R+R_{C}\right)}
\end{array}\right] \\
& B(x)=\left[\begin{array}{c}
\frac{0}{\frac{R_{c} R-R_{M} R_{c}-R_{M} R}{L\left(R_{c}+R\right)}} X_{2}+\frac{R}{L\left(R_{C}+R\right)} X_{3}+\frac{1}{L} V_{\gamma} \\
-\frac{R}{C\left(R+R_{C}\right)} X_{2}
\end{array}\right]
\end{aligned}
$$

By using (30), the derivate $\frac{\partial B(x)}{\partial x}$ is given:

$$
\frac{\partial B(x)}{\partial x}=\left[\begin{array}{ccc}
0 & 0 & 0 \\
0 & \frac{R_{C} R-R_{M} R_{C}-R_{M} R}{L\left(R_{C}+R\right)} & \frac{R}{L\left(R_{C}+R\right)} \\
0 & -\frac{R}{C\left(R+R_{C}\right)} & 0
\end{array}\right]
$$

By adopting (29) and (31) we obtain $\tilde{A}$, and by employing the operation point calculated in (24) and in (30) we obtain $\tilde{B}$. $\tilde{A}$ and $\tilde{B}$ are the linearized state space matrices that we will use to calculate the gains for the state feedback controller.

\section{B. Calculation of the Gain}

First, we need to find the control law [22] of the linear state variables in (32). Then we define the location of the desired closed loop poles by computing the eigenvalues of the open loop system. The poles are adjusted by moving them to the left.

$$
\begin{aligned}
& u=-K x \\
& \dot{x}=A x+B u \\
& \dot{x}=A x+B(-K x)=(A-B K) x \\
& P=\operatorname{eig}(\mathrm{A})
\end{aligned}
$$

It is well known that by using (34), there will be a steady state error in the closed loop system. To compensate, an integral state is added [22]. In addition, $u$ is set, which represents the duty cycle and not the output voltage of the PV generator. To achieve this, an augmented vector and matrices are added [27], taking into account the voltage to be set. Figure 9 shows the state feedback loop of the controller according to (36).

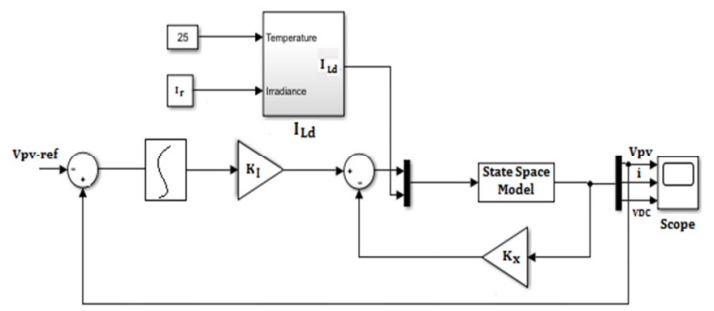

Fig. 9. Integral state feedback controller

The control law of the feedback controller with an integrated control is presented below:

$$
\begin{aligned}
& u=-K_{x} x+K_{I} \int_{0}^{t} e d t \\
& \dot{x_{I}}=C x-y_{\text {ref }}=e
\end{aligned}
$$

with:

$$
e=y-y_{\text {ref }} \text { and } \quad x_{I}=\int_{0}^{t} e d t
$$

Using (33) and (37), the augmented state matrix becomes:

$$
\left[\begin{array}{c}
\dot{x} \\
\dot{x_{I}}
\end{array}\right]=\left[\begin{array}{cc}
A & 0 \\
C & 0
\end{array}\right] x+\left[\begin{array}{c}
B \\
0
\end{array}\right] u+\left[\begin{array}{c}
0 \\
-1
\end{array}\right] y_{\text {ref }}
$$

which results in the following feedback law:

$$
u=-\left[\begin{array}{ll}
K_{X} & K_{I}
\end{array}\right]\left[\begin{array}{l}
x \\
x_{I}
\end{array}\right]
$$

where $y=\left[\begin{array}{ll}C & 0\end{array}\right]\left[\begin{array}{l}x \\ x_{I}\end{array}\right]$ and $C=\left[\begin{array}{lll}1 & 0 & 0\end{array}\right]$.

The column vector $x$ contains the state variables of the system presented in (18). After choosing the appropriate poles:

$$
P=\left[\begin{array}{llll}
-150 & -55+250 \mathrm{i} & -55-250 \mathrm{i} & -110
\end{array}\right]
$$

The gain matrix $K$ is determined by using Ackerman's formula implemented in Matlab:

$$
K=\operatorname{acker}(A, B, P) \text { with } K=\left[\begin{array}{ll}
K_{X} & K_{I}
\end{array}\right]
$$

which gives the following:

$$
\begin{aligned}
& K_{X}=\left[\begin{array}{lll}
0.0175 & 0.8236 & -0.0072
\end{array}\right], \\
& K_{I}=\text { [3.2482] }
\end{aligned}
$$

\section{Choosing $V_{\text {ref }}$}

$V_{\text {ref }}$ denotes the reference voltage and is adjusted so that the PV array can provide maximum power extraction. The reference voltage depends on the sun irradiation and the load. The design rules of the boost converter and the dynamic behavior of the system must be taken into consideration. Let's consider the case of $I_{r}=1000 \mathrm{w} / \mathrm{m}^{2}$. Five panels in series give:

$$
V_{p v-M P P T}=335 \mathrm{~V}
$$

and five panels in parallel are equal to:

$$
I_{p v-M P P T}=4.5 \mathrm{~A}
$$

(see Table I), so by using (9): $R_{p v} \cong 75 \Omega$, and considering Section III, the load must be in this case equal to or greater than $75 \Omega$.

$$
\begin{aligned}
& V_{p v-M P P T}=5 * V_{\text {panel-MPPT }} \\
& I_{p v-M P P T}=5 * I_{\text {panel-MPPT }} \\
& P_{p v-M P P T}=V_{p v-M P P T} * I_{p v-M P P T}
\end{aligned}
$$

We know that: $V=R i$

$$
\text { and } P_{p v-M P P T}=P_{D C}=V i
$$

So by (50) and (51) we get:

$$
P_{D C}=R i^{2} \rightarrow i_{D C}=\sqrt{\frac{P_{D C}}{R}}
$$

$R=100 \Omega$ is chosen. Then by using (49) and (52), $i_{D C}=3.8826 \mathrm{~A}$. $I_{p v-M P P T}=4.5 \mathrm{~A}$ is calculated by (48). Hence, by adopting (8), the duty cycle is equal to 0.1372 , which matches the value given by the simulation shown in Figure 11. 
According to (7) and (50) $V_{r e f} \cong 335 \mathrm{~V}$, which results in $V_{r e f}=V_{p v-}$ $M P P T$.

\section{SIMULATION AND VALIDATION OF THE CONTROL APPROACH}

Figure10 shows the simulation results with the designed and implemented controller. It demonstrates the response of the system according to different values of irradiation $(500,1000$, and 800), and it shows that the desired maximum power is reached for $I r=$ [1000 800]. Furthermore, the rules of the boost are verified, where $V_{p v}<V_{D C}, i_{p v}>i_{D C}$, and the duty cycle is equal to the theoretical value given by (8). In addition, the PV voltage follows the reference value, whereby the state feedback controller is verified under variable irradiation. However, theoretically, the maximum power for $I r=500 \mathrm{w} / \mathrm{m}^{2}$ must be $750 \mathrm{~W}$ and not $500 \mathrm{~W}$. How can this be explained? Let us take (52) with $R=100 \Omega$ and $P_{D C}=750 \mathrm{~W}$. We obtain $i_{D C}=2.74 \mathrm{~A}$ or in this case $i_{p u}=2.245$. According to the rule of the boost, the photovoltaic current must be greater than the output current, which is impossible when $R=100 \Omega$. Therefore, by using (52), $R$ must be greater than $150 \Omega$. Therefore, the maximum power that can be reached in this case is $500 \mathrm{~W}$. Then by using $R=160 \Omega$, and the correspondingly calculated voltage value $V_{\text {ref }}$ the maximum power point is reached (Figure 11). Therefore, the system is robust because it will work under variable values of sunlight and load.
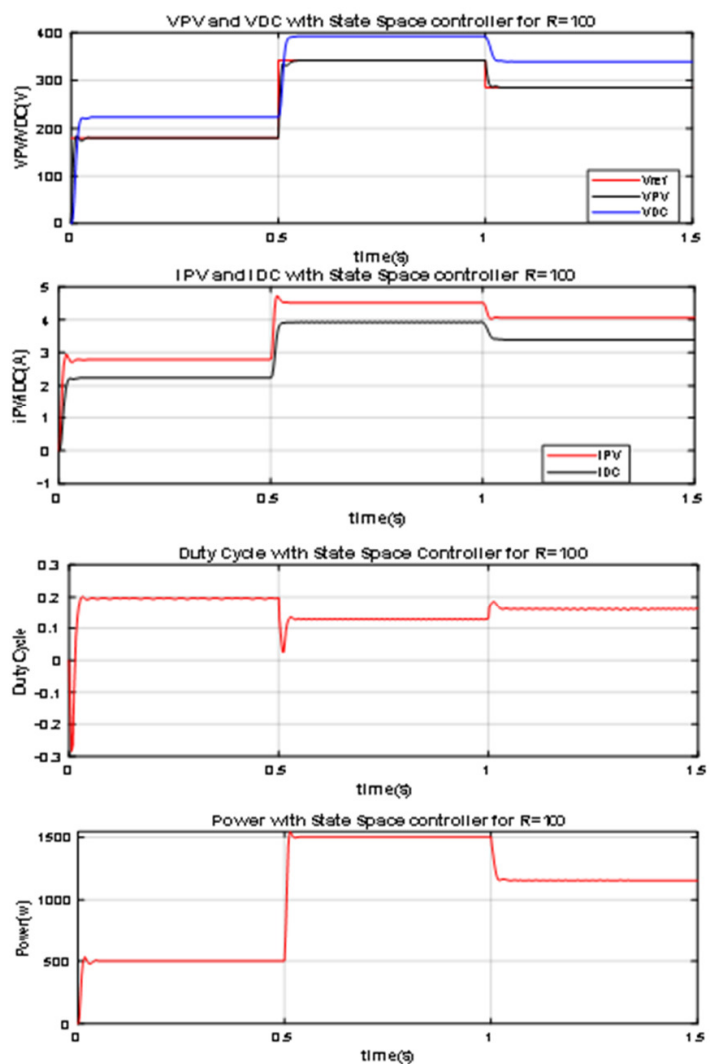

Fig. 10. Curve of the states of the model with power and duty cycle for $\mathrm{R}=100$
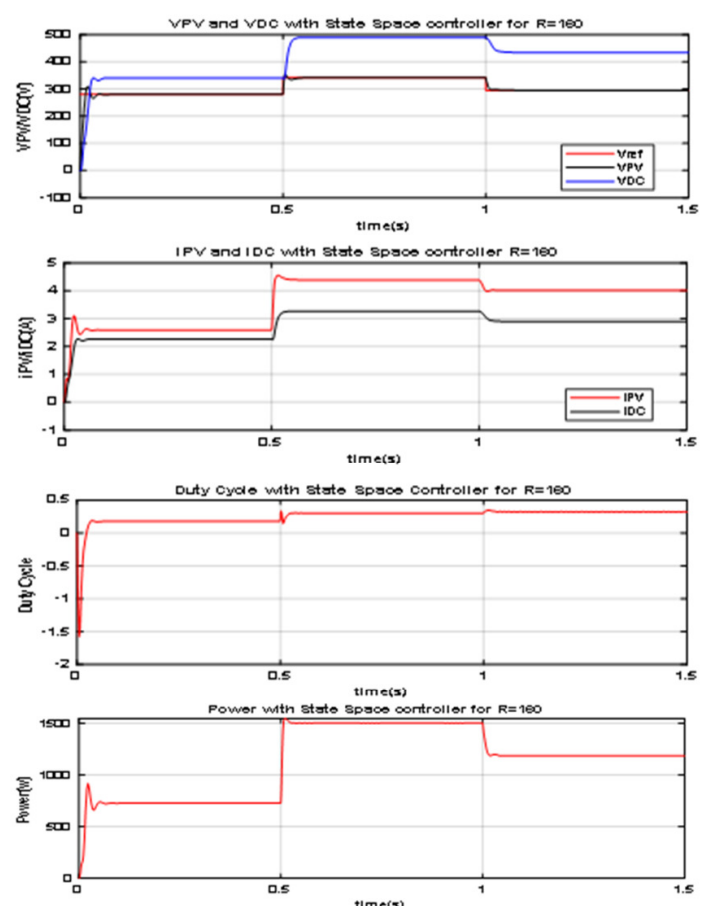

Fig. 11. Curve of the states of the model with power and duty cycle for $\mathrm{R}=160$

\section{DISCUSSION AND OUTLOOK}

Based on the simulation results shown in Figure 11, the predefined control objectives were achieved. For each considered irradiation, maximum power was reached under various loads. The boost was limited by some rules, which were discussed. Because of the load change, the reference value needs to be recalculated to obtain desired maximum power. In some cases, the load will be less than $R_{P V}$. To achieve maximum performance in such cases, a buck converter instead of a boost converter is required. As shown, boost or buck converter alone is not sufficient to operate a solar system autonomously in the optimal state at different loads. A buckboost converter is the solution for variable load. The value of the reference will not be changed because it will be generated automatically by the feedback loop of the controller. The behavior of the PV generator connected to a boost converter was demonstrated. A reliable and efficient method for controlling the boost converter was presented. The robustness of the control system was tested in load changes, and the influence of fluctuating solar radiation on the dynamics of the closed control loop was investigated. The next step in future research is to build a control design for a buck-boost converter and combine it with a wind turbine that operates a hybrid generator.

\section{APPENDIX}

$\begin{array}{ll}\text { Parameters of Kaneka GSA 060 } \\ \text { Maximum power } & 60.3 \mathrm{~W} \\ \text { Voltage in mpp } & 67 \mathrm{~V} \\ \text { Current in mpp } & 0.9 \mathrm{~A} \\ \text { Open-circuit voltage } & 91.8 \mathrm{~V} \\ \text { Short-circuit current } & 1.19 \mathrm{~A}\end{array}$




\section{REFERENCES}

[1] V. Khare, S. Nema, P. Baredar, "Solar-wind hybrid renewable energy system: A review", Renewable and Sustainable Energy Reviews, Vol. 58, pp. 23-33, 2016

[2] IRENA, Renewable Energy Technologies: Cost Analysis Series. Solar Photovoltaics, Vol. 1: Power Sector, No. 4/5, IRENA, 2012

[3] Q. Liand, P. Wolfs, "A review of the single-phase photovoltaic module integrated converter topologies with three different DC link configurations", IEEE Transactions on Power Electronics, Vol. 23, No. 3, pp. 1320-1333, 2008

[4] R. Ingudam, R. Nayak, "Modelling and performance analysis of dc-dc converters for PV grid connected system", International Journal of Science, Engineering and Technology Research, Vol. 4, No. 5, pp. 13781390, 2015

[5] R. Faranda, S. Leva, "Energy comparison of MPPT techniques for PV systems", WSEAS Transactions on Power Systems, Vol. 3, No. 6, pp. 446-455, 2008

[6] G. Vijay, D. K. Palwalia, "A novel analysis and modeling of boost and buck converter", International Journal of Electronics, Electrical and Computational System, Vol. 6, No. 3, 2017

[7] I. Anand, S. Senthilkumar, D. Biswas, M. Kaliamoorthy, "Dynamic power management system employing single stage power converter for standalone solar PV applications", IEEE Transactions on Power Electronics, Vol. 33, No. 12, pp. 10352-10362, 2018

[8] M. S. Jamri, T. C. Wei, "Modeling and control of a photovoltaic energy system using the state-space averaging technique", American Journal of Applied Sciences, Vol. 7, No. 5, pp. 682-691, 2010

[9] S. Jain, V. Agarwal, “A new algorithm for rapid tracking of approximate maximum power point in photovoltaic systems", IEEE Power Electronics Letters, Vol. 2, No. 1, pp. 16-19, 2004

[10] S. S. Kondawar, U. B. Vaidya, "A comparison of two MPPT techniques for PV system in Matlab Simulink”, International Journal of Engineering Research and Development, Vol. 2, No. 7, pp. 73-79, 2012

[11] M. G. Villalva, E. Rupert F., "Analysis and simulation of the P\&O MPPT algorithm using a linearized PV array model”, 35th Annual Conference of IEEE Industrial Electronics, Porto, Portugal, November $3-5,2009$

[12] D. A. Fernandes, M. K. Vieira, M. A. Vitorina, F. F. Costa, P. C. Ribeiro, "Modeling and state-space feedback control of a DC-DC converter for photovoltaic systems", 2014 IEEE Energy Conversion Congress and Exposition (ECCE), Pittsburgh, USA, September 14-18, 2014

[13] M. C. Mira, A. Knott, O. C. Thomsen, M. A. E. Andersen, "Boost converter with combined control loop for a stand-alone photovoltaic battery charge system", 14th Workshop on Control and Modeling for Power Electronics, Salt Lake City, USA, June 23-26, 2013

[14] N. Blaire, A. P. Dobos, J. Freeman, T. Neises, M. Wagner, T. Ferguson, P. Gilman, S. Janzou, System Advisor Model, SAM 2014.1.14: General Description, National Renewable Energy Laboratory, 2014

[15] https://sam.nrel.gov/

[16] https://de.mathworks.com/help/physmod/sps/powersys/ref/pvarray.html

[17] A. R. M. Sahab, M. T. Mirzaee, K. Ghorbany, "The state space average model of boost switching regulator including all of the system uncertainties", Advanced Materials Research, Vol. 403-408, pp. 34763483, 2012

[18] C. Cabal, Optimisation energetique de l'etage d'adaptation electronique dedie a la conversion photovoltaique, $\mathrm{PhD}$ Thesis, Universite Toulouse III - Paul Sabatier, 2008 (in French)

[19] I. Batarseh, A. Harb, Power Electronics: Circuit Analysis and Design, Springer, 2018

[20] K. Kassmi, M. Hamdaoui, F. Olivie, "Conception et modélisation d'un systeme photovoltaique adapte par une commande MPPT analogique", Revue des Energies Renouvelables, Vol. 10, No. 4, pp. 451-462, 2007 (in French)

[21] Y. Chen, B. Zhang, Equivalent-small-parameter analysis of DC/DC switched-mode converter, Springer, 2018
[22] G. F. Franklin, J. D. Powell, A. Emami-Naeini, Feedback Control of Dynamic Systems, Addison-Wesley Publishing Company, 2005 